\title{
Work environment investments: Critical elements for success in optimizing occupational health and safety effects
}

\author{
Alexis Rydell*, Ing-Marie Andersson, Carl-Olof Bernsand and Gunnar Rosén \\ Dalarna University, Falun, Sweden
}

Received 20 December 2017

Accepted 4 November 2018

\begin{abstract}
.
BACKGROUND: A considerable amount of money is invested annually in workplaces to promote creative, comfortable and safe work environments. The processes and effects of these investments are however not sufficiently studied.

OBJECTIVE: The objective of this article is to examine work environment investment processes and identify organizational critical elements for optimizing investment in terms of occupational health and safety effects for employees.

METHODS: Twelve case studies were conducted in different sectors. The data was collected through interviews, by studying available documents, and, in several cases, observations and measurement of hazards by means of the PIMEX-method.

RESULTS: The empirical results yielded seven different critical elements for work environment investment processes. The critical elements identified were: identifying the need, risk assessment, involvement of staff, consultation with OHS expertise, procurement and delivery, implementation and training of workers, and evaluation.

CONCLUSIONS: The critical elements have wide similarities with steps outlined in Swedish Work Environment Management processes, and ideas described in the Plan-Do-Act-Check model. If organizations follow this process, they are provided with improved possibilities for maximizing invested money for a safer working environment.
\end{abstract}

Keywords: Safe workplaces, systematic work environment management, improvement measures, change process

\section{Introduction}

The global cost of work-related injury and illness is estimated at approximately 2680 billion Euros [1]. Consequently, a considerable amount of money is invested annually in workplaces to help produce a creative, comfortable and safe work environment. The fact that these investments are wellmotivated, both from the perspective of the employee, as well as company owners and society at large, is widely agreed upon. Nonetheless, recent studies have shown that great potential exists in further optimizing work environment investments in terms of decreas-

*Address for correspondence: Alexis Rydell, Dalarna University, 79188 Falun, Sweden. Tel.: +46237789 25; E-mail: ary@du. se. ing hazards and improving safety outcomes in the workplace [2].

Plan-Do-Act-Check are the generally described basic steps when measures are needed in workplaces to improve the work situation. This complies with internationally implemented legislation on how to ensure a safe working environment. For example, in the European Union this is regulated in a directive [3], which introduces as key elements the principle of risk management and defines its main elements. These steps are also an essential part in the World Health Organization (WHO) model for achieving healthy workplaces [4]. In this model, which consists of eight steps, the core principals are leadership engagement and workers' involvement [4].

In Sweden, the minimum requirements specified at workplaces from a social perspective are con- 
trolled by law, and by provisions from the Swedish Work Environment Authority. The Swedish Work Environment regulation of Systematic Work Environment Management (SWEM) [5] stresses, among other things, that employers on a systematic basis are required to investigate, follow-up and take action to prevent accidents and illness among staff. This includes both psychological, social and physical aspects of the work environment [5]. The SWEM can be seen as a process where management and employees (or their representatives) in collaboration should examine the work environment, investigate incidents and accidents, conduct risk assessments, develop action plans and implement improvement measures, and evaluate the results in terms of risk elimination. The main aim of the SWEM process is to improve the work environment [5]. Annually, the Swedish Work Environment Authority have follow-up projects to examine how well SWEM is adhered to within different industries. Over the past two years, they have found that out of 1700 visited workplaces, more than half of the workplaces failed in their SWEM responsibility, while in a second study, it was found that eight out of ten of 2000 workplaces failed in their SWEM responsibility $[6,7]$.

Moreover, according to Swedish regulations, an employer should consult external occupational health expertise if the competence is not available within the employer's own organization. If necessary, the employer should sign a contract with the Occupational Health Service (OHS) on preventive measures [5]. Since the beginning of 1990, the OHS competes with companies in the free market [8], while in recent years, they have formed fewer and larger organizations [9]. However, these changes have not contributed to better marketing and collaboration with small enterprises [9]. Schmidt [10] stresses that it is not the size of the OHS service provider but rather the importance of a long-term relationship between the OHS service provider and the client company that provides access to, and the benefit of, the expertise that the OHS can offer.

Companies can apply different models, or be inspired by them, for their change processes. Ideally, these models describe important phases and critical elements in order to succeed with the change process at hand. Kotter [11, 12], for instance, describes an organizational change model which includes the following eight steps: establishing a sense of urgency, creating a guiding coalition, developing a vision and strategy, communicating the vision of change, empowering broad-based action, generating short- term wins, consolidating gains and producing more change, and anchoring new approaches in the culture. Furthermore, Heracleous [13] has developed a five-step model, which includes situation analysis, policy and strategic formulation, consequences for organization, leadership of change, and monitoring and evaluation. He also points out the importance of change, work consisting of visible, active and clear leadership, participatory planning, and communication that supports understanding, and the development of knowledge and roles [14].

Other types of models that are interesting to study in this context of work environment investments are organizational project models. A project is often defined as a task that is solved during a limited time period and by a defined team with specific resources $[15,16]$. A project-based approach is a suitable way to organize when deciding and implementing organizational change, not least it makes it easier to overcome resistance [15]. However, it is important to apply the correct change model and change roles, in order to enable the project organization to focus on the organizational change process [17]. The intention with the project is defined by the goals, which normally are set by the project owner [15]. The boundaries are commonly defined by time limits, the project team, goals, and resources [16]. In fact, without the boundaries there is no clear difference between projects and the daily business of the organization [16].

Pinto and Slevin [18] have detected ten key factors for a successful project, which, among other factors, are: project mission, project schedule/plan, personnel, monitoring and feedback. Other researchers also include these factors. Turner and Müller [15], and Turner and Cochrane [19], for instance, argue that clear goals and objectives are one of the main elements in controlling and managing projects. Goals also make it easier to start training before the project ends, and thus simplify transition to the daily business of the organization [20]. Moreover, good relations with the stakeholders and users, for instance, by letting them participate and contribute in the process will allow for smoother implementation [21], as well as ensuring that the goals are reached [15].

Common for all these described models is that they address a change process, whereby the organization goes from one state of conditions to another, which, in turn, should improve the organization's effectiveness and competitiveness. When it comes to work environment changes and improvements, the focus is especially on creating healthier and safer workplaces. The aim of this article is to examine work 
Table 1

Included cases and type of investment

\begin{tabular}{|c|c|c|}
\hline Cases & Organization & Work environment factor/type of investment \\
\hline 1 Office & Municipality & $\begin{array}{l}\text { Ergonomic intervention to minimize } \\
\text { musculoskeletal disorder }\end{array}$ \\
\hline 2 Office & Private company & $\begin{array}{l}\text { Ergonomic intervention to minimize } \\
\text { musculoskeletal disorder }\end{array}$ \\
\hline 3 Joinery & Private company & Exhaust equipment to minimize wood dust \\
\hline 4 Joinery & Private company & Exhaust equipment to minimize wood dust \\
\hline 5 Welding hall & Private company & $\begin{array}{l}\text { Exhaust equipment to minimize welding } \\
\text { fumes }\end{array}$ \\
\hline 6 Welding hall & Educational center & $\begin{array}{l}\text { Exhaust equipment to minimize welding } \\
\text { fumes }\end{array}$ \\
\hline 7 Mechanical workshop & Private company & Accident prevention at metal processing \\
\hline 8 Laser cutting & Private company & Exhaust equipment to minimize laser fumes \\
\hline 9 Spray station & Private company & Exhaust equipment to minimize solvent \\
\hline 10 Food distributor & Private company & $\begin{array}{l}\text { Equipment to minimize musculoskeletal } \\
\text { disorder }\end{array}$ \\
\hline 11 Canteen & Municipal Company & Equipment to minimize noise \\
\hline 12 Manufacturing & Private company & Equipment to minimize vibration \\
\hline
\end{tabular}

environment investment processes and identify organizational critical elements for optimizing investment in terms of occupational health and safety effects for employees. In this article, the focus is on work environment investment that has already been made over the past couple of years.

\section{Method and material}

Twelve case studies were conducted at workplaces in Sweden where recent investments have been made to improve the working environment with different starting points and goals (see Table 1). In essence, the case studies have concentrated on various technical investments, which have focused on both musculoskeletal ergonomic risks and accidents, as well as chemical and physical hazards, such as exposure to air contaminants, noise and vibration. Hence, the work environment investments made vary, regarding the magnitude and costs for the organization. The average investment cost was approximately 30000 Euros. The twelve cases (eight organizations) also differ in terms of number or employees in the organization, where one organization is a municipality finance department, five organizations can be categorized as small-sized enterprises, while two organizations are larger enterprises, as defined by the European Commission [22].

The context under which the included organizations operate are, inter alia, the Swedish legalization concerning the Work Environment Act, which includes SWEM and other safety obligations for the prevention of accidents or illness at work [23]. Under this Act, management is required to cooperate with safety representatives, appointed by the unions or employees, in issues regarding safety and the work environment [23].

The data in this study was collected from 2015-2017. The data collection is based on interviews, observations and measurement of hazards, conducted by means of the picture mixture exposure (PIMEX)-method, and by studying available documents. The use of several methods (and multiple cases) provided a richness of data for the study [24]. Different types of company documents were available in approximately half of the cases and included: risk assessments, protocols, procurement documents and reports. These documents covered additional information regarding decisions and work processes. Documents are useful because they can provide information and details of events [25].

Semi-structured interviews were carried out with top management, managers, employees, and, sometimes, safety representatives, at each organization. The purpose of the interviews was to collect knowledge about the work process and the perceived outcomes of the investment made. The interviews followed an interview templet, highlighting areas, such as: background of the investment, motive for the investment, the decision-making process, the implementation phase, perceived outcomes and evaluation of the investment. Several questions, combined with follow-up questions, were asked to the respondents in each of these areas. The interview template was created after studying extent research and legal requirement dealing with OHS issues in Sweden, after thorough discussion within the research group, 
as well as with the advisory group in the project. In total, 43 interviews were carried out across eight organizations.

In each interview situation, at least two researchers participated, where one researcher asked the questions while the other took meticulous notes. In order to obtain an overview of the interviews, a table including background and key information was created [26]. The interviews were analyzed thematically by finding key patterns of perceived important phases or topics in the work environment investment process. The results of the interviews were discussed extensively within the research group and later on with the advisory group. The purpose of this was to ascertain the robustness of the result. The findings of this analysis process resulted in the seven critical organizational elements presented in this article.

To complement the interviews and collect information regarding the effects of investments, observations were carried out in applicable cases by means of measurement and real-time monitoring of hazards, combined with video filming, labeled as the picture mixture exposure (PIMEX)-method [27]. These applicable cases included investments aimed at decreasing workers' exposure to air containments, such as solvents, welding fumes and wood dust, or measures taken to reduce hand/arm vibrations. Altogether, the study using the PIMEX-method was carried out in eight of the twelve work environment investment cases. In essence, the method involves filming the employee conducting the work, and simultaneously measuring hazards in the breathing zone for air contaminants. Hand/arm vibration was monitored on the handle of the tools, and noise was measured with a microphone installed in the studied room. Thereafter, the equipment, system, or work process was adjusted, in order to remeasure air containments or other physical hazards, thus enabling the researchers to evaluate changes in exposure levels between the two work practices and provide the basis for risk communication [2, 27]. The PIMEX method was shown to be an effective method for illustrating risks and for changing the behavior of employees, enabling them to work more safely [28].

\section{Results}

This section describes the empirical results from the twelve cases, in terms of how the organizations conducted the work environment investments, before, during and after the investment was made.
Table 2

Actions taken in the different critical elements

\begin{tabular}{llc}
\hline Case & $\begin{array}{l}\text { Work environment } \\
\text { factor/type of } \\
\text { investment }\end{array}$ & $\begin{array}{c}\text { Reduced exposure } \\
\text { after training } \\
\text { with PIMEX \% }\end{array}$ \\
\hline 3 Joinery & $\begin{array}{l}\text { Exhaust equipment to } \\
\text { minimize wood dust } \\
\text { 5 Welding hall }\end{array}$ & 100 \\
& $\begin{array}{l}\text { Exhaust equipment to } \\
\text { minimize welding } \\
\text { fumes }\end{array}$ & 82 \\
6 Welding hall & $\begin{array}{l}\text { Exhaust equipment to } \\
\text { minimize welding } \\
\text { fumes }\end{array}$ & 85 \\
9 Spray station & $\begin{array}{l}\text { Exhaust equipment to } \\
\text { minimize solvent }\end{array}$ \\
12 Manufacturing & $\begin{array}{l}\text { Equipment to minimize } \\
\text { vibration }\end{array}$ \\
\hline
\end{tabular}

The results follow the structure of the identified critical elements in the process, namely: identifying the need, risk assessment, involvement of staff, consultation with external experts, procurement and delivery, implementation and training of workers, and lastly, evaluation of the investment made. Table 2 illustrates actions taken in the different critical elements in the twelve studied cases.

\subsection{Identify the need}

All twelve cases identified a need for investment in the work environment, but this need arose in different ways and for different reasons, identified from different hierarchic levels in the organizations. In some cases, the need was identified by management, but in most cases it was identified by the employees working on the shop floor. When identified by management, the need was often due to regulatory standards and issues, or in connection with some other major planned change in the production line. On the other hand, in those cases where the need for improvement was identified by employees, it was often based on inadequately functioning of systems or work equipment. Here, the workers in their everyday practical work practice had experienced obstacles and, therefore, requested alternative solutions in order to be able to conduct the work task safely and effectively. The employees highlighted regular meetings as one suitable arena for identifying and discussing the need for improvement in the work environment, as well as a means for reaching consent with management regarding improvement measures. 


\subsection{Risk assessment}

In the majority of the cases studied, legally required risk assessment had not been carried out before deciding on investing in the work environment. In two cases no risk assessment at all had been made. Eight cases had performed informal estimations of the risks, which were, however, considerably insufficient according to Swedish legal requirements. For instance, these informal estimations included identifying vulnerable employees to be prioritized when conducting the improvement measures in office settings, or using rather informal noise measurements. Only two cases had made stipulated reliable risk assessment by measuring levels of exposure (e.g. air containment risks) in industrial settings. In these two latter cases, occupational hygiene measurements showed values close to, or above, Swedish limit values. The reason for carrying out the risk assessment was primarily based on gathering facts and knowledge about the need and direction of the investment. The reasons why the other ten cases had not made legally required risk assessments vary, but include examples such as, economical limitations, and lack of knowledge and understanding among managers about the importance of risk assessments.

\subsection{Involvement of staff}

In seven of the twelve cases, the employees perceived that they had been involved in the investment processes of acquiring new equipment or systems. In general, the employee involvement centered around what type of new equipment should be acquired, as well as demands and specifications on the supplier and the new products. In several of these cases, the employees' opinions, knowledge and experience, were important before deciding on the type of new equipment or system to purchase. In the other five cases, on the contrary, the interviewed employees perceived that they had not been involved in the investment process, indicating that management had decided on the investment on their own without any integrative consultation with the staff. Reasons for the very low, or non-existing, employee involvement were primarily based on lack of knowledge, and leadership style and characteristics. However, managers and employees did not agree in all cases on the degree of actual employee involvement, where some managers stated that the employees had been involved in the process, while the employees claimed otherwise. One explanation for this was that the management had provided information on the Intranet, considering this as sufficient for employee involvement in the process, while the employees regarded this as inadequate.

\subsection{Consultation with external OHS expertise}

In four of the twelve cases, the management had contact with external expertise prior to the investment. In addition, two of the larger organizations had access to integrated OHS expertise, but only one of these organizations used the expertise during the process. Discussions were held with experts with different skills, and in one case, several different experts were involved in discussions. In the cases where OHS was contacted, safety engineers based their involvement in the investment discussions on risk assessments in the form of exposure measurements for noise, vibration and welding smoke, or from previous experience. In an organization where it was relevant to update employees' knowledge of good office work environment, the management contacted the OHS consultant and their ergonomist for the task. None of the experts had participated in any evaluation of the investment after the implementation.

\subsection{Procurement and delivery}

Variations between the twelve cases and how the procurement was achieved differ substantially. In three cases, procurement was carried out with manufacturers/consultants which the company already had supplier agreements with. In these cases, the companies requested solutions from the suppliers regarding improvements in the work environment. These were cases where office furniture and education were procured. In four cases, solutions and actual concepts were bought after being discovered at exhibitions, or through other connections, while in one case, the management trusted those who took part in the development of the equipment. Suppliers were contacted, based on previous work relations in two cases. These cases concerned accident prevention in metal processing, and welding extraction equipment at a private company. In two cases, two suppliers were invited to offer a tender for the job, and, on the basis of this, the company selected one of the suppliers. In another case, there were extensive procedures with clear requirements and the suppliers were invited to discuss, explain and justify their offer. The most common procurement specifications regarded capacity and dimensions of the invested equipment. 
When necessary, the equipment was mounted by the supplier, which occurred in all cases, except for two. In one of these two cases, the equipment was simply delivered, and then the workstation was designed and built by the employees, whereas in the other case, the delivered equipment had to be mounted and adjusted to the existing machines and systems by the employees.

Notably, in one case, the installation was not ready after one year because the organization was still waiting for electricians to connect the control equipment and lights to the machines. The installation had, however, low priority for the organization.

\subsection{Implementation and training of workers}

Extensive training was given to the employees in one case, and minor training was given in five cases. Extensive training included a lecture for the staff by OHS experts. The lecture was then followed up in the office of each employee with personal instructions and training in ergonomics to ensure healthy work positions and conditions. The training was characterized by active participation among the staff. Minor training meant short information to the employees or managers about how the system technically functions. In one case, the managers assembled the employees to discuss and inform them how to manage and handle the new equipment.

However, in six cases, no training was given. One explanation for this was that the management did not think that there was any need for training, since they believed that the equipment was easy to use. In addition, in the vast majority of cases (eleven), there was no training in how to use the equipment in an optimal and efficient way to achieve a safe work environment.

In five of the eight workplaces where the PIMEX method was used, exposure to air contaminants and vibration could be drastically reduced when workers learned how to optimize the use of work environment investment by observing themselves in recorded occupational situations. Table 3 illustrates the potential decrease in exposure at the five different workplaces.

Regarding the other three cases where PIMEX was used, in two of these cases, there was no need for employee training in reducing exposure levels during the work process because the exposure levels already were very low, and in the third case, technical installations were required to reach a lower exposure level.

\subsection{Evaluation of the investment}

There was no formal evaluation of the investments from a working environment perspective carried out in any of the twelve cases after the installation and implementation, but, in one case, there was an evaluation of the function from a production perspective. In several cases, nonetheless, managers and employees stated that they perceived better health outcomes and less hazards in the work as a result of the investment. However, employees also reported shortcomings, such as black dust inside a welding helmet. Reasons for not performing any formal evaluations were primarily that management thought that the staff was satisfied and no evaluation was needed, as well as lack of time for conducting evaluations.

\section{Discussion}

This article has examined work environment investment processes, and identified organizational critical elements for succeeding with this process and optimizing investment in terms of occupational health and safety effects for employees. Seven critical organizational elements were identified, namely: identification of the need, risk assessment, involvement of staff, consultation with external expertise, procurement and delivery, implementation and training of workers, and lastly, evaluation of the investment. The twelve different work environment cases revealed different results regarding action taken and effectiveness in relation to these seven critical elements. However, the vast majority of the cases indicate a rather unstructured and reactive position regarding the process, which is remarkable, since a considerable amount of money was invested in each case.

Previous well-known organizational change theories and models $[12,13,29-31]$ highlight different perspectives and important steps for management to consider when deciding and implementing organizational change processes. The model (i.e. critical elements) developed in this article is somewhat similar to some steps in previous organizational change models, but also differs substantially in several ways, not least since it focuses on a specific type of change process, namely work environment investment that is targeted to change and affects employees' work situation positively. Similarities with other change models are primarily connected to aspects, such as identifying the need for change, employee involvement, implementation and evaluation. 


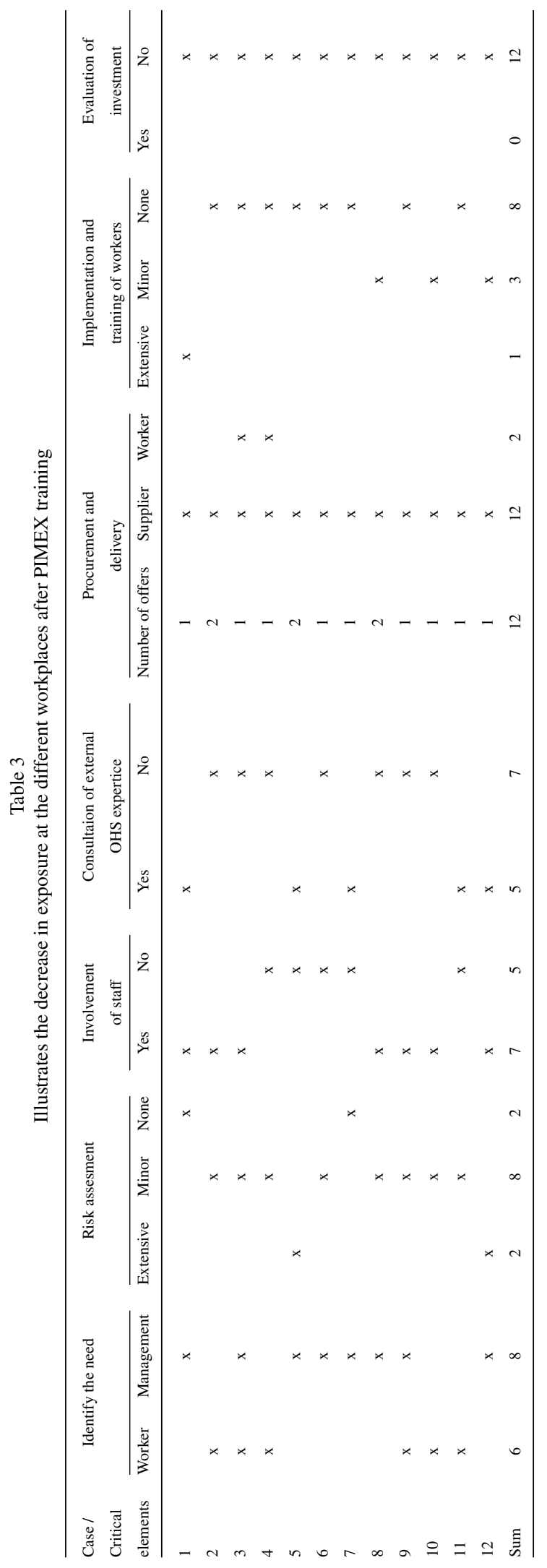


The uniqueness of the present developed work environment investment model (critical elements) is the focus on the entire investment process for optimizing the effects, in terms of creating a safer work environment. As Rydell and Andersson [2] have shown, by following up three work environment investment cases, investments can be highly optimized through further decreasing hazards for workers. For optimizing the effects of the investments, Rydell and Andersson found that employee involvement, safety training, leadership engagement and follow-ups of the investment are important. However, our study reveals that it is not only these aspects that organizations should consider when starting and implementing the investment process. Many of the twelve cases indicate a lack of systematic approach in several important phases, for example, in risk assessment, consultation with external expertise, and procurement and evaluation phases. Indeed, if organizations act more thoughtfully and wisely during these phases, a better implementation of the investment can occur, which, in turn, can affect the safety outcomes positively.

Risk assessments are a fundamental part of a well-designed program for work environment improvements. Employers are also by law obliged to document such risk assessments [5], but, as illustrated in this study, assessments are too often non-existent, or are of poor quality. This finding is in line with conclusions from the Swedish Work Environment Authority's yearly evaluation projects concerning the SWEM [6, 7]. Poor risk assessments can often be explained by limited knowledge among managers about needs and regulations, but also the fact that correct and formal risk assessments are considered too expensive. Even if investment in technical terms is very effective, is it very often so that the potential effect on hazard reduction depends on an interplay between the user and technology. This is typically the case with, for example, welding exhausts and ergonomic aids. A possible effect typically depends on the quality of the equipment, in combination with knowledge in effective use and motivation for usage. Motivation, in this case, clearly depends on to what extent the worker has been involved in the process [32]. Positive results can occur when employees with experience from current work are involved in the design process, where new solutions are developed to ensure a healthier and safer work environment [33].

A successful result of an investment for the creation of a good and healthy workplace also depends on the fact that necessary knowledge about the pre- requisites is in place. This is often not available within the organization and, therefore, managers often trust in suppliers and their knowledge. However, it is mandatory to consult OHS expertise when knowledge within the company is not enough [5]. Yet, several of the included cases did not choose to consult with the OHS in the process. Through long-term cooperation with the OHS, their expertise can be effectively renewed when planning work environment investments [10]. This is an expertise that often is missing among many smaller companies in Sweden, and also by most of the investigated workplaces in this study. An explanation for not using OHS expertise could be the fact that many SMEs have limited (economical) resources, as is the case especially with smaller SMEs [34].

Failure in the procurement and delivery phase is very much related, depending on the lack of risk assessments and definitions of desired goals for the investment. In none of the cases studied was a clear demand on expected work environment effects included in the contract, due to lack of expertise knowledge. Without a clear description of the work situation before the procurement and the change process, definitions of any expected effect will be non-existent or unclear. However, the procurement usually lacks information about effective use of hazard control, since this falls outside the agreement.

Regarding training, this should have an engaging and participating approach, in order to increase knowledge and change behaviors to enable workers to conduct the work safely [35]. Furthermore, businesses become more effective when the organization invests in training of the workers [36]. However, in the reported empirical cases, comprehensive and participating training was not prioritized, except for one case that explicitly focused on such a training structure to increase knowledge. By using the PIMEX method, it became possible to show the effect of training. In the five cases where the method could be used optimally to visualize how work environment investment could be adapted to work and best work practice, exposure levels for the workers decreased by more than 80 percent, in relation to the situation after the investment, but with limited or no training aimed at effective use.

In addition, without quantified risk assessment in how the situation was before the change, it is almost impossible to evaluate the after-effect. In most reported cases, the responsible managers were unable to clarify if the intended results were achieved, which implies that they could not see if the potential effect of the investment was realized because of lack 
of knowledge regarding evaluations. The managers and the employees often perceived an improvement resulting from the investment, which satisfied them, and, therefore, they did not conduct a formal evaluation. However, employees and managers subjectively perceived that improvements shown have not been enough [2], and to create a safer work environment actions need to be taken based on the results of a formal evaluation [4].

\subsection{Methodological considerations and further research}

The twelve included work environment investment cases are from different industrial sectors - including different types of organizations - and cover a range of different OHS issues. Several methods were used to analyze the investment process and outcomes, which provided a richness of data [24]. Yet, it should be noted that the cases provided different opportunities for combining some of the included methods, in particular, observations through the PIMEX-method. Since the PIMEX-method in this project focused on air contaminants and physical hazards, such as noise and vibration, the method could only be used in eight out of twelve cases. The other cases, which focused on investments in musculoskeletal ergonomics and protection improvement, measures were, therefore, more dependent on the interviews conducted to analyze the importance of, for instance, training.

This study also revealed a lack of proper documentation of the investment process, in several of the organizations studied. Approximately half of the organizations had formal documentation of the investment process available, and even fewer (two organizations) had made legally required risk assessments before deciding on the investment. This indicates that investments in the work environment, by the studied Swedish companies, are often not based on thorough and proper analysis or procurement considerations.

Studies have found that work environment investment can be highly optimized in terms of OHS effects [2]. This study confirms these results, but also highlights the importance of focusing on the whole investment process, which, in this study, emerged in seven critical elements. Further research could therefore focus on an in-depth study of managers' perceptions regarding a systematic approach to investment processes, and the implementation of the above presented model. In addition, further research could investigate managers' and safety representa- tives' competencies in the different steps of work environment investments.

\section{Conclusions}

In conclusion, the identified organizational critical elements in this study are consistent with ideas outlined by SWEM, and the Plan-Do-Check-Act model. If organizations follow this process, it provides improved possibilities for maximizing effective use of invested money, thus leading to a safer working environment. The critical elements where the organizations showed most shortcomings are: legally required risk assessment, consulting with external expertise, safety training, and evaluation of the investment. This study also reveals that many organizations do not follow Swedish legislation regarding SWEM when investments are made aiming at improved OHS.

\section{Acknowledgments}

This research was financed by AFA Insurance in Sweden.

\section{Conflict of interest}

None to report.

\section{References}

[1] European Agency of Safety and Health at Work. An international comparison of the cost of work-related accidents and illnesses. [Internet]. Santiago de Compostela: European Agency of Safety and Health at work; 2017. [cited 2017 December 13]. Available from: https://osha.europa.eu/en/ tools-and-publications/publications/international-comparis on-cost-work-related-accidents-and/view.

[2] Rydell A, Andersson I-M. Work environment investments: Outcomes from three cases. Int J Occup Saf Ergon. 2019;25(1):138-147.

[3] European Agency of Safety and Health at work. Directive 89/391/EEC - OSH "Framework Directive" [Internet]. Santiago de Compostela: European Agency of Safety and Health at work; 1989. [cited 2017 December 13]. Available from: https://osha.europa.eu/en/legislation/directives/theosh-framework-directive/1.

[4] World Health Organization. Healthy workplaces: A model for action. For employers, workers, policy-makers and practitioners [Internet]. Geneva: World Health Organization; 2010. [cited 2017 Dec 13]. Available from: http://www.who. int/occupational_health/publications/healthy_workplaces_ model_action.pdf. 
[5] The Swedish Work Environment Authority. Provision about Systematic Work Environment Management [Internet]. Stockholm; 2001. [cited 2017 Dec 13]. Available from: http://av.se/dokument/inenglish/legislations/eng0101.pdf.

[6] The Swedish Work Environment Authority. [Internet]. Bred tillsyn att $\mathrm{f}_{a}^{\circ}$ ner olyckstalen inom tillverkning och partihandel. [Broad supervision to reduce the accident rate in manufacturing and wholesale]. Stockholm; 2016 [updated 2016 Feb 29; cited 2018 June 15]. Available from: https://www.av.se/press/bred-tillsyn-for-att-faner-olyckstalen-inom-tillverkning-och-partihandeln/.

[7] The Swedish Work Environment Authority. [Internet]. Krafttag krävs för att lyfta arbetsmiljöarbetet. [Strong measures are required to highlight work environment efforts]. Stockholm; 2017 [updated 2017 Oct 27; cited 2018 June 15]. Available from: https://www.av.se/press/krafttag-kravs-foratt-lyfta-arbetsmiljoarbetet/.

[8] Bohlin L, Hjalmarsson L. Occupational health services in Sweden. Policy and Practice in Health and Saf. 2007;(5): 113-23.

[9] Schmidt L, Gunnarsson K, Dellve L, Antonsson A-B. Utilizing occupational health service in small-scale enterprises: A 10-year perspective. Small enterp Res. 2016;23(2):101-15.

[10] Schmidt L, Sjöström J, Antonsson A-B. Is ownership the decisive factor in collaborations between occupational health services and client companies. Work. 2016;56(2): 309-18.

[11] Kotter JP. Leading Change. Boston, Mass.: Harvard Business School Press; 1996.

[12] Kotter JP. Leading Change: Why Transformation Efforts Fail. Harvard Bus. Rev. 1995;59-67.

[13] Heracleous L. An Ethnographic Study of Culture in the Context of Organizational Change. The J of App Behavioral Sci. 2001;37(4):426-46.

[14] Svenningsson S, Sörgärde N. Organisationsförändringar från ingenjörskonst till tolkning. In: Mats Alvesson, Stefan Svenigsson (Eds.), Organisationer, Ledning och Processer. Lund: Studentlitteratur, 2013, pp. 231-361.

[15] Turner RJ, Müller R. On the nature of the project as a temporary organization Int. J of proj manag 2003;21(1):1-8.

[16] Lundin RA, Söderholm A. A theory of the temporary organization Scand. J of manag. 1995;11(4):437-55.

[17] Gareis R. Changes of organizations by projects. Int J of proj manag. 2010;28(4):314-27.

[18] Pinto JK, Slevin DP. Critical factors in successful implementation. IEE Transactions of eng manag. 1987;34(1):22-7.

[19] Turner JR, Cochrane RA. Goals-and-methods matrix: Coping with projects with ill-defined goals and/or methods of achieving them. Int J of proj manag. 1993;11(2):93-102.

[20] Somers TM, Nelson KG. A taxonomy of players and activities across the ERP project life cycle. Inf and manag. 2004;41(3):257-78.

[21] Munns AK, Bjeirmi BF. The role of project management in achieving project success. Int $\mathbf{J}$ of proj manag. 1996;14(2):81-7.
[22] Centre for Strategy \& Evaluation Services. Final Report Evaluation of SME definition [Internet]. DirectorateGeneral for Enterprise and Industry European Commission 2014 [cited 2018 June 29]. Available from: \\dustaff $\backslash$ home $\backslash$ ima $\backslash$ Documents $\backslash$ Dokument-aktuella $\backslash$ PROJEKT $\backslash$ a-Investering-effekt $\backslash$ Art ikel2 $\backslash$ Granskare juni 18\} Evaluation of the SME definition - EU Law and Publications.html.

[23] The Swedish Work Environment Authority. About the Work Environment Act. [Internet]. Stockholm 2017. [cited 2018 June 25]. Available from: https://www.av.se/en/workenvironment-work-and-inspections/acts-and-regulationsabout-work-environment/the-work-environment-act/aboutthe-work-environment-act/.

[24] Stavros C, Westberg, K. Using triangulation and multiple case studies to advance relationship marketing theory. Qualitative Market Research: An International Journal. 2009;12(3):307-20.

[25] Yin R. Qualitative research from start to finish. Guilford Press, cop. New York; 2011

[26] Trost J. Kvalitativa intervjuer. [Qualitative Interviews]. Studentlitteratur. Lund; 2010.

[27] Rosén G, Andersson I-M,Walsh PT, et al. A review of video monitoring as an occupational hygiene tool. Annu Occup Hyg. 2005; 49(3):201-7.

[28] Kuhl K, Dobernowsky M. Application of PIMEX method: Employees are motivated to change their working conditions and optimise preventive measures. Work. 2011;39(4):379-84.

[29] Burke WW. Organizational Change: Theory and Practice. 4th ed. Thousand Oaks, CA: Sage; 2014.

[30] Batras D, Duff C, Smith BJ. Organizational change theory: Implications for health promotion practice. Health Promot Int 2016;31(1):231-41.

[31] Cameron E, Green M. Making Sense of Change Management. 4th. ed. KoganPage: London; 2015.

[32] Hedlund A, Gummesson K, Rydell A, Andersson I-M. Safety Motivation at Work: Evaluation of Changes from Six Interventions. Saf Sci. 2016;82:155-63.

[33] Bittencourt JM, Duarte F, Beguin P. From the past to the future: Integrating work experience into the design process. Special Section: Work and Sustainable Development. Work. 2017;57(3):379-87.

[34] Legg SJ, Olsen KB, Laird IS, Hasle P. Managing safety in small and medium enterprises. Saf Sci. 2015;71(Part C):189-96.

[35] Burke MJ, Sarpy SA, Smith-Crowe K, Chan-Serafin S, Salvador RO, Islam G. Relative Effectiveness of Worker Safety and Health Training Methods. Am J of public health. 2006;32(2):315-24.

[36] González X, Miles-Touya D, Pazó C. R\&D, worker training and innovation: Firm-level evidence. Industry and Innovation. 2016;23(8):694-712. 